\title{
Role of biomarkers in predicting the occurrence of thyroid neoplasms in radiation-exposed children
}

\author{
Joseph M Shulan, Leonid Vydro, Arthur B Schneider and Dan V Mihailescu \\ Division of Endocrinology, Diabetes and Metabolism, University of Illinois at Chicago, Chicago, Illinois, USA
}

Correspondence should be addressed to D V Mihailescu: danmih@uic.edu

\begin{abstract}
With increasing numbers of childhood cancer survivors who were treated with radiation, there is a need to evaluate potential biomarkers that could signal an increased risk of developing thyroid cancer. We aimed to examine the relationships between thyrotropin and thyroglobulin levels and the risk of developing thyroid nodules and cancer in a cohort of radiation-exposed children. 764 subjects who were irradiated in the neck area as children were examined and followed for up to 25 years. All subjects underwent a clinical examination, measurements of thyrotropin, thyroglobulin levels and thyroid imaging. At baseline, 216 subjects had thyroid nodules and 548 did not. Of those with nodules, 176 underwent surgery with 55 confirmed thyroid cancers. During the follow-up, 147 subjects developed thyroid nodules including 22 with thyroid cancer. Thyroglobulin levels were higher in subjects with prevalent thyroid nodules $(26.1 \mathrm{ng} / \mathrm{mL}$ vs $9.37 \mathrm{ng} / \mathrm{mL} ; P<0.001)$ and in those who had an initial normal examination but later developed thyroid nodules $(11.2 \mathrm{ng} / \mathrm{mL}$ vs $8.87 \mathrm{ng} / \mathrm{mL} ; P=0.017)$. There was no relationship between baseline thyrotropin levels and the prevalent presence or absence of thyroid nodules, whether a prevalent neoplasm was benign or malignant, subsequent development of thyroid nodules during follow-up or whether an incident nodule was benign or malignant. In conclusion, in radiation-exposed children, higher thyroglobulin levels indicated an increased risk of developing thyroid nodules but did not differentiate between benign and malignant neoplasms. There was no association between the baseline TSH level and the risk of developing thyroid nodules or cancer.
\end{abstract}

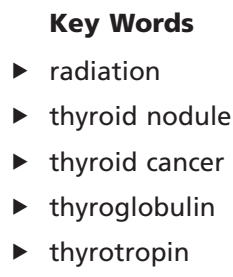

Endocrine-Related Cancer (2018) 25, 481-491

\section{Introduction}

Radiation-induced thyroid cancer remains an important clinical concern. Although the medical use of radiation for treating benign head and neck conditions has been abandoned, the risks associated with the use of such treatments in the middle of last century persists for decades after the exposure; currently, radiation is frequently used to treat children with cancer and, as of 2013 , over 400,000 survivors are alive in the United States; and nuclear accidents, such as those at Chernobyl and Fukushima, remain possible (Sinnott et al. 2010, Wheatley et al. 2017). In addition, exposure to ionizing radiation in the general population of the U.S. has doubled between 1980 and 2006, mostly due to diagnostic radiological testing (NCRP 2009). 
While several studies have attempted to identify biomarkers that are predictive of the likelihood of malignancy in patients with thyroid nodules in the general population, the data correlating these factors in radiation-induced thyroid cancer remain scarce. Several publications have shown that the risk of malignancy in sporadic thyroid nodules increases with serum thyrotropin (TSH) concentrations, even within the normal range (Boelaert et al. 2006, Haymart et al. 2008, Witczak et al. 2016). In contrast, in a case-control analysis matching thyroid cancer cases with controls nested in the European Prospective Investigation into Cancer and Nutrition cohort (EPIC) study, Rinaldi and coworkers found that thyroid cancer risk was negatively associated with the TSH levels (Rinaldi et al. 2014). In addition, the EPIC study found that high thyroglobulin (Tg) levels preceded the diagnosis of thyroid cancer by almost a decade. The predictive value of these biomarkers in radiation-exposed individuals has not yet been determined.

The objective of the current analysis was to evaluate the predictive value of baseline TSH and Tg levels for the development of thyroid nodules and cancer in radiationexposed patients. The study is based on a cohort of subjects irradiated for benign conditions in the head and neck area and examined in 1974, both at Michael Reese Hospital in Chicago, and followed prospectively thereafter. We performed a cross-sectional analysis using the presence or absence of nodules and cancer found at the 1974 examinations (prevalent cases) and a longitudinal study of nodules and cancers that developed during the follow-up of subjects whose initial examination was normal (incident cases).

\section{Patients and methods}

\section{Radiation-exposed cohort}

The cohort consisted of 4296 subjects who were younger than 16 years when they were treated with radiation to the head and neck region for benign conditions from 1939 to 1962 at Michael Reese Hospital in Chicago. A Thyroid Follow-up Program began in 1974 with an effort to contact all of the irradiated patients, to inform them about their radiation exposure and to invite them to participate in the study (Favus et al. 1976). The study was reviewed and approved by the Michael Reese Hospital and later by the University of Illinois at Chicago Institutional Review Boards.

This study includes all members of the cohort whose first visit occurred between January 3, 1974 and September 24,1974 , with a total of 887 subjects (Fig. 1). Of these, 81 were excluded for the following reasons: 33 had thyroid surgery prior to visit, 47 were taking levothyroxine at time of or within six months of TSH measurement,

\section{Subjects with measured TSH and Tg at initial study visit}

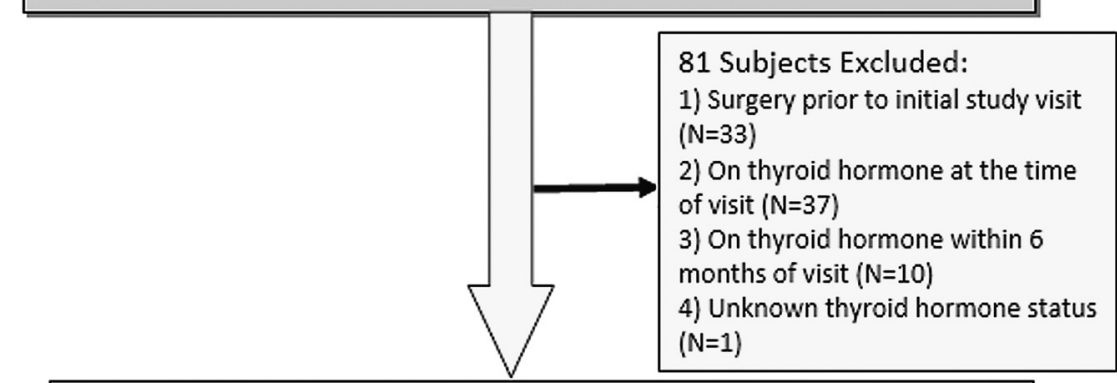

806 Subjects underwent physical examination and Tcpertechnetate scanning

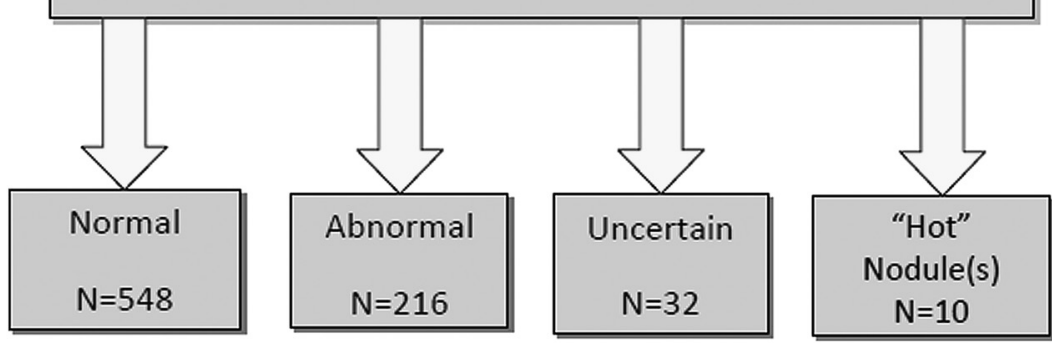

Figure 1

Subject exclusions resulting in the 806 subjects included in this study and their diagnostic categories from their initial evaluation. 
and for 1 , whether or not they were taking thyroid hormone was not recorded, leaving a total of 806 subjects. Of the 806 subjects, 511 (63.4\%) were males. Participants underwent a clinical evaluation, which included a physical examination of the head and neck area with palpation of the thyroid gland, measurements of plasma $\mathrm{TSH}$, plasma Tg levels, anti-Tg antibodies and thyroid imaging (Favus et al. 1976). Imaging in 1974 consisted of thyroid scanning using Tc-pertechnetate with a pinhole collimator to obtain anterior and oblique images. Any nodule with uptake higher than the surrounding thyroid was considered 'hot.' When a 'hot' nodule was seen, the scan was repeated using ${ }^{123}$ I. Isotopic scans were replaced by thyroid ultrasonography when it became available years later. Of the 424 subjects with recorded follow-up, 72 of them had a total of 147 thyroid ultrasound examinations performed (Schneider et al. 1997). When the scan findings were considered 'uncertain,' the subject was asked to return in six months for a repeat evaluation. When nodules were detected, subjects were referred to their physicians for management.

\section{Laboratory tests}

A modification of the assay using NIH provided reagents was used to ascertain plasma TSH, as previously described (Schneider et al. 1977, Frohman et al. 1982). Contemporaneously, the upper limit of normal was reported as $6 \mathrm{IU} / \mathrm{L}$ with a sensitivity of $0.5-1.0 \mathrm{IU} / \mathrm{L}$ and, later, the intra- and inter-assay coefficients were reported to be $7.2 \%$ and $11.9 \%$, respectively (Schneider et al. 1977, Williams et al. 1988). The Tg assay was performed using a modification of the radioimmunoassay first described by Van Herle and coworkers (Van Herle et al. 1973, Schneider et al. 1977). The least detectable concentration was $0.8 \mathrm{ng} / \mathrm{mL}$. Determination of the $\mathrm{Tg}$ level in the plasma and serum gave identical results. The withinassay coefficient of variation was $5.2 \%$ and betweenassay coefficient of variation was $12.8 \%$ for the range of $3.5-36 \mathrm{ng} / \mathrm{mL}$. Samples resulting in greater than an $85 \%$ displacement of the tracer were diluted and re-assayed. Anti-Tg antibody levels were measured using a tanned erythrocyte agglutination kit as previously described (Schneider et al. 1977). Subjects $(N=37)$ with positive antibodies $(\geq 1: 20)$ were excluded from all analyses relating to $\mathrm{Tg}$. Measurements of $\mathrm{TSH}$ and $\mathrm{Tg}$ below their sensitivity levels were included in analyses at the sensitivity level.

\section{Statistical analysis}

To evaluate the relationships between the baseline TSH and Tg levels measured at the 1974 visit and prevalent (present at the time of the initial examination) thyroid nodules and incident cases (found during follow-up), we performed cross-sectional and longitudinal analyses. In the cross-sectional component, we examined whether the baseline TSH and Tg levels were associated with the presence or absence of nodules at the time the levels were drawn. We then determined whether the TSH and Tg levels were associated with cancer in those with thyroid nodules who underwent surgery within one year as a result of a finding at the initial visit. Subjects found to have a malignant nodule were excluded from any analyses related to benign nodules. Chi-square tests were used to compare outcome frequencies of males and females.

In the longitudinal component, we analyzed whether the TSH and Tg levels measured at the initial visit were related to the incident thyroid nodules and with the risk of cancer in those nodules.

Independent sample $t$-tests were used to analyze the difference in mean TSH and Tg values between benign/ cancer groups as well as normal and abnormal groups in both the cross-sectional and longitudinal analysis. Potential covariates, radiation dose to the thyroid, age at radiation treatment, age at initial visit and, for longitudinal studies, attained age were also tested. When any were significant by $t$-test, logistical analysis was used to determine the effect on the principal associations. For the longitudinal analysis comparing TSH and Tg in those who developed nodules to those who did not, Cox analysis was used. The time course of nodule development during follow-up was determined by Kaplan-Meier analysis. For all analyses except the Cox analysis and the receiver-operating characteristic (ROC) curves, TSH and Tg levels were logtransformed to normalize their distributions. In the Cox analyses, the hazard ratio for the actual TSH and Tg levels and their associated significance levels were the outcomes of interest. Given the limited number of incident thyroid cancers (22 cases), Cox analysis was not performed for them. Pearson correlation was used to determine whether there was a correlation between TSH and Tg levels at the initial visit and the size of the prevalent thyroid cancers. When significant associations were found, quartile categories were calculated based on the distribution of the level of the respective biomarker. Odds ratios (ORs) and their corresponding 95\% confidence intervals (CIs) were calculated comparing the upper quartile with the lowest 
quartiles. In addition, ROC curves and their parameters were calculated for those analyses.

Systat, version 13 (San Jose, CA, USA) was used for statistical analyses. Significance was determined using a $P$ value of $<0.05$.

\section{Results}

\section{Cross-sectional study}

Based on their physical examination and Tc-pertechnetate and, when indicated ${ }^{123}$ I, thyroid scan, the 806 subjects were categorized as follows: 547 were normal, 186 were abnormal, 68 were uncertain and 5 had hot nodules. Of the 68 subjects whose result was uncertain, 49 were reevaluated on follow-up visits within one year when
13 continued to be classified as uncertain, 30 were reclassified as abnormal, 5 were found to have hot nodules and 1 was reclassified as normal. As a result, the final number of patients classified as normal was 548, as abnormal 216, 32 as uncertain and 10 with hot nodules (Fig. 1). Subjects with uncertain findings and hot nodules were excluded from all the analyses. Within one year of the initial visit, a total of 176 subjects had thyroid surgery, 119 had only benign findings, 55 had cancer and pathology findings were not available for 2 . We counted all cases of thyroid cancer, including those found 'incidentally' during surgery that was indicated for a different nodule. Subjects who were found to have coexistent malignant and benign nodules were included in the cancer category. Similarly, analyses of subjects with benign nodules excluded those with malignant ones.

Table 1 Characteristics, TSH and thyroglobulin level ( \pm 1 S.D. shown in parentheses) for the subjects in the cross-sectional analyses.

\begin{tabular}{|c|c|c|c|}
\hline & Abnormal examinationa & Normal examinationa & $P$ value \\
\hline Subjects $(N)$ & 216 & 548 & \\
\hline Age at radiation (years) & $4.03(1.3 ; 6.7)$ & $4.32(1.18 ; 7.38)$ & 0.219 \\
\hline Thyroid dose (cGy) & $65.2(37.3 ; 93.2)$ & $55.6(25.3 ; 85.7)$ & $<0.001$ \\
\hline Age at initial examination (years) & $31.7(26.8 ; 36.7)$ & $31.4(26.2 ; 36.6)$ & 0.557 \\
\hline TSH (IU/L) & $2.34(1.22 ; 4.65)$ & $2.30(1.30 ; 4.09)$ & 0.545 \\
\hline \multirow[t]{2}{*}{$\operatorname{Tg}(\mathrm{ng} / \mathrm{mL}) \mathrm{c}$} & $26.1(9.03 ; 75.4)$ & $9.37(3.67 ; 23.9)$ & $<0.001^{d}$ \\
\hline & Cancer & Benign & \\
\hline Subjects $(N)$ & 55 & 119 & \\
\hline Age at radiation (years) & $4.02(1.13 ; 6.90)$ & $3.71(1.26 ; 6.16)$ & 0.497 \\
\hline Thyroid dose (cGy) ${ }^{\mathrm{b}}$ & $73.8(25.1 ; 122.5)$ & $64.0(27.5 ; 90.5)$ & 0.185 \\
\hline Age at initial examination (years) & $32.2(27.0 ; 37.5)$ & $31.1(26.5 ; 35.7)$ & 0.192 \\
\hline TSH (IU/L) & $2.06(1.08 ; 3.94)$ & $2.25(1.12 ; 4.55)$ & 0.409 \\
\hline \multirow[t]{2}{*}{$\mathrm{Tg}(\mathrm{ng} / \mathrm{mL})^{\mathrm{c}}$} & $27.1(10.0 ; 73.7)$ & $25.1(8.17 ; 76.9)$ & 0.657 \\
\hline & Abnormal examination & Normal examination & \\
\hline \multicolumn{4}{|l|}{ Men } \\
\hline Subjects $(N)$ & 118 & 373 & \\
\hline \multirow[t]{2}{*}{ TSH (IU/L) } & $2.25(1.16 ; 4.36)$ & $2.28(1.27 ; 4.10)$ & 0.849 \\
\hline & Cancer & Benign & \\
\hline \multicolumn{4}{|l|}{ Men } \\
\hline Subjects $(N)$ & 28 & 64 & \\
\hline \multirow[t]{2}{*}{ TSH (IU/L) } & $1.85(0.82 ; 4.44)$ & $2.10(1.10 ; 4.00)$ & 0.662 \\
\hline & Abnormal examination & Normal examination & \\
\hline \multicolumn{4}{|l|}{ Women } \\
\hline Subjects $(N)$ & 98 & 175 & \\
\hline \multirow[t]{2}{*}{ TSH (IU/L) } & $2.27(0.86 ; 6.06)$ & $2.20(1.01 ; 4.80)$ & 0.740 \\
\hline & Cancer & Benign & \\
\hline \multicolumn{4}{|l|}{ Women } \\
\hline Subjects $(N)$ & 27 & 55 & \\
\hline TSH (IU/L) & $1.69(0.55 ; 5.23)$ & $2.29(0.90 ; 5.82)$ & 0.202 \\
\hline
\end{tabular}

aNormal examination (no nodules); abnormal examination (nodules present); bdoses were not determined for 15, 59, 5 and 9 abnormal, normal, cancer and benign subjects, respectively; 'Tg not included in the presence and anti-Tg antibodies in $8,22,3$ and 4 abnormal, normal, cancer and benign subjects, respectively; din logistic regression, both $\mathrm{Tg}(P$ value $<0.001)$ and dose $(P$ value 0.016$)$ remained significant. 


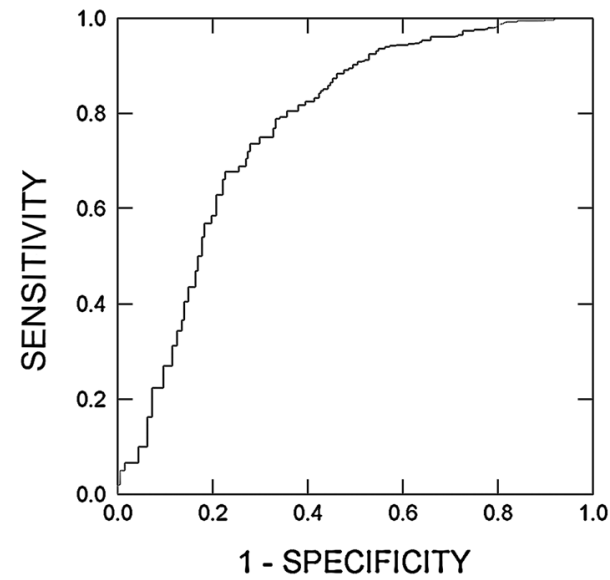

Figure 2

ROC curve for Tg levels and the presence of nodules at the time of the baseline Tg measurements.

\section{Relationship between TSH and Tg levels and prevalent thyroid nodules}

The group of subjects with nodules was compared to the group with normal examination findings (Table 1). For TSH levels, there was no significant difference between the groups $(2.30 \mathrm{IU} / \mathrm{L}$ vs $2.34 \mathrm{IU} / \mathrm{L} ; P=0.55)$. The dose to the thyroid gland was significantly higher in subjects with nodules (65.2cGy vs 55.6cGy, $P<0.001$ ). Tg levels at baseline were also significantly higher in the group with nodules $(26.1 \mathrm{ng} / \mathrm{mL}$ vs $9.37 \mathrm{ng} / \mathrm{mL} ; P<0.001)$. In multivariate logistic models, both dose to the thyroid gland and Tg level remained significant $(P=0.016$ and $P<0.001$, respectively). Figure 2 shows the ROC curve for $\mathrm{Tg}$ levels and the presence of nodules at the time of $\mathrm{Tg}$ measurements. The area under the curve for this crosssectional analysis was 0.778 . A Tg cut point of $24.38 \mathrm{ng} / \mathrm{mL}$ (the juncture of the seventh and eighth octile), gives a sensitivity of $54.8 \%$ (95\% CI: $47.8-61.7 \%$ ), a specificity of $87.0 \%$ (83.8-89.7\%), a positive predictive value of $62.3 \%$ (54.2-68\%) and a negative predictive value of $83.0 \%$ (80.8-85.1\%).

\section{Relationship between TSH and Tg levels and the presence of cancer in the prevalent thyroid nodules}

As a result of findings at the first visit, 174 subjects had surgery within one year. Cancers were found in 55 of these subjects and benign nodules in 119 of them (Table 1). There was no difference between the TSH levels of subjects with benign and malignant nodules $(2.25 \mathrm{IU} / \mathrm{L}$ vs $2.06 \mathrm{IU} / \mathrm{L} ; P=0.41$ ) (Fig. 3A). Similarly, there was no difference in $\mathrm{Tg}$ levels between the subjects in these two groups (25.1 ng/mL vs $27.1 \mathrm{ng} / \mathrm{mL} P=0.66)$, although the
$\mathrm{Tg}$ levels in both of these groups were higher than the $\mathrm{Tg}$ levels in those with a normal examination $(9.37 \mathrm{ng} / \mathrm{mL}$; $P<0.001$ for both comparisons). When 26 of the cancers $\leq 10 \mathrm{~mm}$ were excluded, the findings remained the same. We also examined whether there was a correlation between TSH and Tg levels and thyroid cancer size in the 55 subjects with thyroid cancer. Neither coefficient was significant; 0.087 for TSH $(P=0.522)$ and 0.001 for $\mathrm{Tg}$ $(P=0.993)$.

Relationship between gender, TSH levels and the presence of prevalent thyroid nodules and cancer

At the initial visit, 118 of 491 (24.0\%) of males and 98 of $273(35.9 \%)$ of females had abnormal examinations $(P<0.001)$. Twenty-eight of the 491 males $(5.7 \%)$ and 27 $(9.9 \%)$ of the 273 females had thyroid cancer $(P=0.032)$. We have analyzed cross-sectional TSH levels separately for male and female subjects with benign or malignant nodules. For men, the mean TSH level for those with malignant nodules was $1.85 \mathrm{IU} / \mathrm{L}(0.82 \mathrm{IU} / \mathrm{L} ; 4.44 \mathrm{IU} / \mathrm{L})$ and $2.10 \mathrm{IU} / \mathrm{L}(1.10 \mathrm{IU} / \mathrm{L} ; 4.00 \mathrm{IU} / \mathrm{L})$ for those with benign

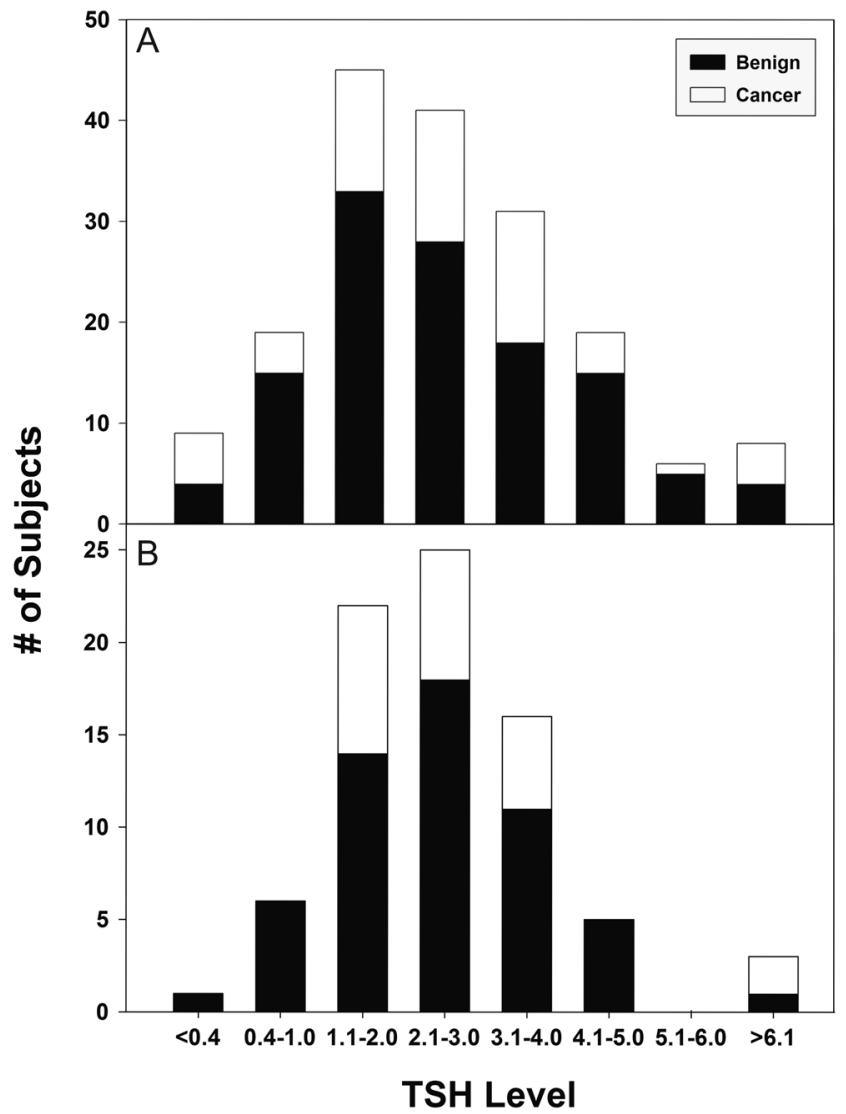

Figure 3

Distribution of subjects with benign and malignant nodules diagnosed at their initial visit (A) or during follow-up (B) based on TSH ranges. 
Table 2 Characteristics and TSH and thyroglobulin level ( \pm 1 S.D. shown in parentheses) for the subjects in the longitudinal analyses.

\begin{tabular}{l} 
Subjects $(N)$ \\
Age at radiation (years) \\
Thyroid dose (cGy) \\
Age at initial examination (years) \\
Attained age (years) ${ }^{b}$ \\
TSH (IU/L) \\
Tg (ng/mL)c \\
\hline \\
\hline Subjects $(N)$ \\
Age at radiation (years) \\
Thyroid dose (cGy) \\
Age at initial examination (years) \\
Attained age (years) ${ }^{d}$ \\
TSH (IU/L) \\
Tg (ng/mL)c
\end{tabular}

\begin{tabular}{c}
\hline No nodules \\
277 \\
$4.59(1.27 ; 7.90)$ \\
$55.1(22.8 ; 87.4)$ \\
$31.9(26.8 ; 37.0)$ \\
$49.2(38.5 ; 58.8)$ \\
$2.28(1.24 ; 4.20)$ \\
$8.87(3.38 ; 23.3)$ \\
Cancer \\
22 \\
$3.59(0.65 ; 6.52)$ \\
$55.9(37.0 ; 74.9)$ \\
$29.1(24.0 ; 34.2)$ \\
$38.0(29.0 ; 47.0)$ \\
$2.47(1.53 ; 3.98)$ \\
$11.5(3.83 ; 34.3)$
\end{tabular}

\begin{tabular}{ccr}
\hline Developed nodules & & P value \\
$3.72(1.28 ; 6.16)$ & & 0.002 \\
$59.0(29.7 ; 89.3)$ & & 0.249 \\
$30.4(25.8 ; 35.2)$ & & 0.002 \\
$43.6(33.2 ; 53.7)$ & & 0.000 \\
$2.31(1.40 ; 3,84)$ & & 0.771 \\
$11.2(4.44 ; 28.5)$ & 0.017 \\
\hline Benign & \\
\hline $3.62(1.21 ; 6.24)$ & \\
$62.2(36.4 ; 88.0)$ & 0.962 \\
$31.1(26.6 ; 35.6)$ & 0.269 \\
$42.6(32.0 ; 53.1)$ & 0.111 \\
$2.11(1.25 ; 3.94)$ & 0.064 \\
$10.8(4.73 ; 24.8)$ & 0.214 \\
\hline
\end{tabular}

aDoses were not determined for 30, 19, 2 and 4 no nodules, developed nodules, cancer and benign subjects, respectively; bage at development of nodule(s) or last vital status; 'Tg not included in the presence and anti-Tg antibodies in 9, 8, 1 and 0 in nodule-free, developed nodules, cancer and benign subjects, respectively; dage at thyroid surgery.

nodules $(P=0.66)$. For females, the same comparison was 1.69 IU/L (0.55 IU/L; 5.23 IU/L) for those with malignant nodules and 2.29 IU/L (0.90 IU/L; 5.82 IU/L) for those with benign nodules $(P=0.20)$ (Table 1$)$.

\section{Longitudinal study}

Of the original 548 subjects who were not found to have thyroid nodules at their initial visit, 424 had follow-up; 277 remained free of nodules, 147 developed nodules and for 124, no follow-up information was available. Of those with nodules, 75 had thyroid surgery and of these 53 were found to have benign nodules while 22 were cancers (Table 2). Of these, 16 of the 48 males (33.3\%) and 6 of the 27 females $(22.2 \%)$ had cancer $(P=0.310)$.

\section{Relationship between initial TSH and Tg levels and the subsequent development of nodules during follow-up}

Of the 424 subjects with an initial normal examination with follow-up, 147 developed nodules after a mean of 12.2 years while 277 after a mean of 17.3 years did not (Table 2). There was no difference comparing the TSH levels for these two groups $(2.3 \mathrm{IU} / \mathrm{L}$ vs $2.2 \mathrm{IU} / \mathrm{L} ; P=0.77)$ (Fig. 3B). When the Tg levels at the initial visit were compared between the two groups, the baseline Tg levels in those who subsequently developed thyroid nodules were significantly higher $(11.2 \mathrm{ng} / \mathrm{mL}$ vs $8.8 \mathrm{ng} / \mathrm{mL}$; $P=0.017)$, compared to those who remained normal. The relative risk for developing thyroid nodules for the subjects in the upper Tg quartile was $1.82(1.39-2.37 ; P=0.025)$ compared with the subjects in the lower Tg quartiles. The area under the ROC curve for baseline Tg levels and the incident thyroid nodules during the follow-up period was 0.563 .

In order to take into account the longer observation time for the subjects who did not develop nodules, proportional hazards (Cox) analysis was performed (Table 3). For TSH, there was no relationship to the subsequent development of nodules $(P=0.734)$. In contrast, the risk of developing nodules increased with increasing Tg levels $(P=0.003)$. The only other significant

Table 3 Proportional hazards (Cox) analyses of TSH and Tg in the longitudinal analysis of developing nodules.

\begin{tabular}{|c|c|c|c|}
\hline Parameter & Mean & Hazard ratio ( \pm 1 S.D.) & $P$ value \\
\hline $\mathrm{TSH}^{\mathrm{a}}$ & 2.69 & $1.017(0.969 ; 1.068)$ & 0.734 \\
\hline $\mathrm{Tg}^{\mathrm{b}}$ & 14.59 & $1.013(1.009 ; 1.017)$ & 0.003 \\
\hline Age at examinationc & 31.44 & $0.943(0.927 ; 0.959)$ & 0.001 \\
\hline \multicolumn{4}{|l|}{ Multipled } \\
\hline $\mathrm{Tg}$ & 14.86 & $1.012(1.007 ; 1.017)$ & 0.011 \\
\hline $\begin{array}{l}\text { Treatment age } \\
\text { (year) }\end{array}$ & 4.26 & $0.997(0.953 ; 1.043)$ & 0.948 \\
\hline Thyroid dose (cGy) & 56.69 & 1.0 & 0.119 \\
\hline $\begin{array}{l}\text { Age at examination } \\
\text { (year) }\end{array}$ & 31.38 & $0.928(0.905 ; 0.953)$ & 0.004 \\
\hline
\end{tabular}

a147 subjects developed nodules and 277 did not; breduced to 139 subject developed nodules and 268 did not due to measurable anti-Tg levels; creduced to 121 subjects with nodules and 238 without due to missing dose estimates; dunivariate (TSH, Tg and age at examination in 1974) and multivariate ( $\mathrm{Tg}$, age at radiation treatment, radiation dose to the thyroid and age at examination) Cox analyses are shown. Printed in Great Britain 


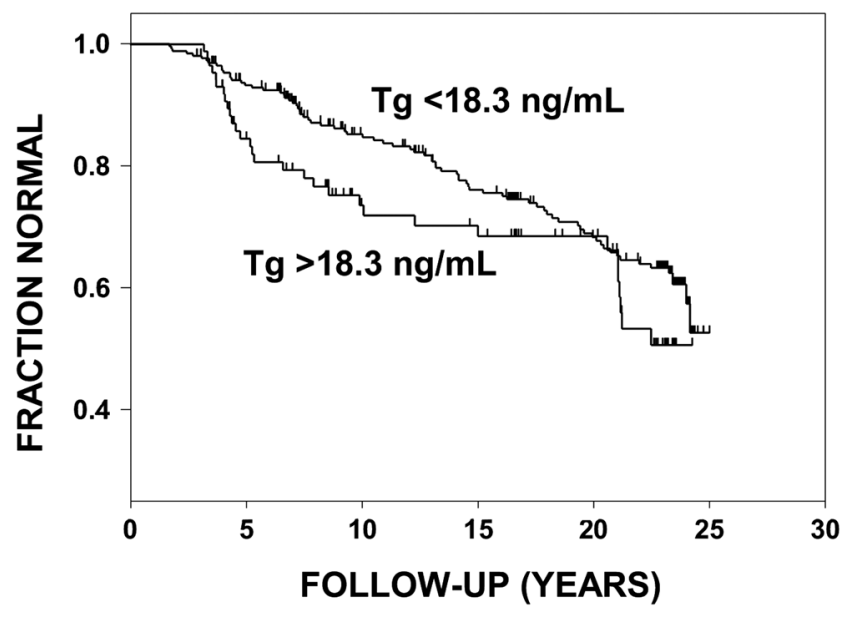

Figure 4

Kaplan-Meier survival curves showing the development of thyroid nodules in subjects with baseline Tg levels in the highest quartile $(>18.3 \mathrm{ng} / \mathrm{mL}$ ) compared with subjects in bottom three quartiles. The former developed more nodules throughout follow-up, although the lines transiently touched at about 20 years.

risk factor was age at the time of the initial visit $(P=0.001)$. Having a baseline Tg level higher than $18.3 \mathrm{ng} / \mathrm{mL}$ (fourth quartile) had a significant effect on the disease-free survival as demonstrated by Kaplan-Mayer curves (Fig. 4). In a multivariate analysis, Tg level and age at initial visit continued to be significant with very similar hazard ratios and significance as in the univariate analyses. Age at treatment and dose were not significant (Table 3 ).

\section{Relationship between initial TSH and Tg levels and whether an incident nodule was malignant}

When initial visit TSH and Tg levels were compared between the benign and malignant groups, no significant differences were found ( $P=0.21$ and $P=0.83$ respectively) (Fig. 2B and Table 2).

\section{Discussion}

Efforts to find predictors of thyroid cancer risk in radiation-exposed subjects remain clinically relevant due to increasing population exposure mainly to ionizing radiation from medical uses, both diagnostic and therapeutic. The NCRP 2009 report (NCRP 2009) estimated that in 2006, compared to the early 1980s, Americans experienced a doubling of ionizing radiation exposure, predominantly from diagnostic medical procedures (Kitahara \& Sosa 2016). Furthermore, the best surveillance methodology for thyroid cancer in radiationexposed subjects, especially survivors of childhood cancer, has not yet been determined.
This study shows an increased risk of developing thyroid nodules in radiation-exposed subjects with higher baseline Tg levels. Serum Tg level has been associated with several thyroid disorders, but its utility as a predictor of thyroid cancer risk has not been firmly established for either sporadic or radiation-induced thyroid cancer. The potential role of $\mathrm{Tg}$ as a predictor of the subsequent development of sporadic thyroid cancer is clearest in the EPIC cohort study (Rinaldi et al. 2014) and in an earlier, smaller study (Thoresen et al. 1988). In the EPIC cohort, Rinaldi and coworkers demonstrated a significant positive association between the Tg levels and thyroid cancer risk $(\mathrm{OR}=9.15)$ and that higher Tg levels may precede the detection of thyroid cancer by up to 8 years (Rinaldi et al. 2014). The data linking Tg levels with thyroid nodules and cancer in radiation-exposed subjects are limited. We previously reported that thyroglobulin levels increased over time in subjects who developed thyroid nodules (Schneider et al. 1985). We also found an association between Tg levels and the absolute number, but not the total volume of thyroid nodules detected by ultrasound (Schneider et al. 1977). The current study shows a positive association between baseline serum Tg levels and the presence or absence of thyroid nodules in a large cohort of radiation-exposed subjects. Interestingly, this association was demonstrated both at the time of the measurement (the cross-section analysis) and longitudinally over more than two decades of follow-up. In the cross-sectional analysis, subjects with abnormal examinations had significantly higher baseline Tg levels and also received a higher radiation dose (Table 1 ). The mean baseline $\mathrm{Tg}$ levels were found to be significantly elevated in subjects with nodular thyroid disease, both benign and malignant compared to normal individuals, but the Tg levels were not different comparing subjects with benign to those with malignant thyroid nodules.

In subjects whose initial examination was normal, $\mathrm{Tg}$ levels and a younger age at the time of the radiation treatment were risk factors for subsequent development of thyroid nodules during follow-up (Table 2). Even though higher baseline Tg levels were able to predict the development of thyroid nodules, they did not differentiate between the benign and malignant ones. Subjects in the upper Tg quartile had a relative risk for developing thyroid nodules almost twice as high as compared with the subjects in the lowest quartile. In accord with our results, serum Tg was found to be significantly related to the development of thyroid abnormalities and nodules in a population-based cohort assembled in Belarus following the Chernobyl nuclear accident (Cahoon et al. 2013). 
Additionally, data from a recent publication, which evaluated 10,430 individuals who were living in Ukraine and were under 18 years of age at the time of the Chernobyl accident, also confirmed higher mean and median Tg levels in participants with abnormal thyroid glands (Peters et al. 2017). Early data from the Fukushima area do not suggest an association between the baseline $\mathrm{Tg}$ levels and either benign or malignant thyroid nodules in the first few years after the accidental radiation exposure, but the long-term follow-up studies are not yet available (Suzuki et al. 2016b). Lando and coworkers evaluated serum Tg levels as a marker of development of thyroid disease in individuals who received neck irradiation for the treatment of childhood cancer (Lando et al. 2003). The authors determined that neck irradiation was associated with significantly higher Tg levels compared with those who were not irradiated, but more importantly, none of the irradiated individuals who had normal Tg levels developed thyroid cancer.

TSH has long been considered as a potential facilitator of thyroid cancer development. Recent studies carried out in general population have found predominantly, but not exclusively, positive associations between TSH levels and the probability that a nodule is malignant. The majority of evidence appears to be that the higher the TSH level, even within the normal range, the higher the risk that a nodule is malignant. Numerous studies have shown the trophic effect of TSH on sporadic thyroid cancer growth (Ichikawa et al. 1976, Carayon et al. 1980) and suppression has been shown to improve relapse-free survival (Pujol et al. 1996). Boelaert and coworkers found in nonradiation-exposed patients that the risk of malignancy rose in parallel with serum TSH levels, especially when the TSH level was great than 1.8U/L (Boelaert et al. 2006). Several other retrospective studies produced similar findings (Haymart et al. 2008, Witczak et al. 2016), but others showed opposing results (Castro et al. 2011, Kim et al. 2011). In a recent nested case-control study of 741 US military personnel diagnosed with PTC cancer and a similar number of matched controls, Huang and coworkers demonstrated an inverse relationship between TSH levels and risk of PTC (Huang et al. 2017). These results were consistent with the data from the larger population-based EPIC cohort (Rinaldi et al. 2014). Huang and collaborators recently showed diametrically different relationships between TSH levels and the probability of malignancy in thyroid nodules between men and women (Huang et al. 2017, Kitahara et al. 2017). We analyzed the sex-specific relationships between TSH and risk of a nodule being malignant in the cross-sectional analysis and found no association between the TSH levels and the risk of malignancy in radiation-exposed men and women, suggesting that the effect of radiation is stronger than gender-related factors.

To the best of our knowledge, whether TSH levels are predictors of malignancy in nodules in radiation-exposed patients has not been evaluated. Cahoon and coworkers reported a correlation between the baseline TSH and Tg levels and thyroid abnormalities in an iodine deficient population living in Belarus at the time of the Chernobyl accident, but did not indicate whether the TSH levels were associated with the risk of thyroid nodules or cancer (Cahoon et al. 2013). Our results show no association between pre-diagnostic TSH levels and the risk that a nodule is malignant in radiation-exposed subjects. In addition, there were no association between the baseline TSH levels and the risk of developing thyroid nodules or cancer during the follow-up period. This difference could potentially be due to the carcinogenic effect of radiation having a larger effect on the development of thyroid nodules and cancer than TSH levels. The dose-response relationship is well documented, with the excess risk remaining elevated at least to 40 years (Schneider et al. 1993, Ron et al. 1995, Veiga et al. 2016). An observation that supports this explanation is seen in tissue specimens from patients with Chernobyl-related thyroid cancers. These specimens showed dose-dependent changes in gene expression, not only in the tumor, but also in the normal thyroid, suggesting that radiation effects can occur in histologically normal tissue and likely represent early steps of carcinogenesis (Abend et al. 2013). In addition, TSH does not act alone or play a dominant role in the development or growth of thyroid cancer, as suggested by in vitro studies with IGF-1 (Derwahl et al. 1999) and by the occurrence of malignant thyroid nodules in suppressed contralateral lobes in patients with autonomously functioning 'hot' nodules (Satta et al. 1993). Further, the EPIC study found a significant negative association between TSH and thyroid cancer with an odds ratio 0.56. Similarly, and more recently, baseline findings from the Fukushima Health Management Survey indicated an association between lower TSH levels and the presence of thyroid nodules and papillary thyroid cancer (Suzuki et al. $2016 a$ ) in children who were exposed to radiation during the nuclear accident. Some authors suggest that a genetic predisposition could explain these results (Rinaldi et al. 2014). Genome-wide association studies identified several genetic variants (e.g. 9q22.23 and 14q13.3) associated with both differentiated thyroid cancer and low TSH values (Gudmundsson et al. 2009, 2012). Also, the association 
with variants on 9q22.33 has been demonstrated in radiation-induced thyroid cancer (Takahashi et al. 2010). It is unknown if subjects in our cohort had such genetic predispositions, which could have further influenced TSH levels.

Children treated with radiation for malignancy are at high risk of developing hypothyroidism and active surveillance is recommended. It has been proposed that early or even prophylactic thyroid hormone treatment could reduce the development of thyroid cancer. The TSH-related findings reported here do not support this possibility.

Another finding was that age at the time the Tg and TSH levels were measured was negatively associated with the subsequent development of thyroid nodules. The difference between the ages at initial visit for those who developed nodules (mean of 30.4 years) and those who did not (31.9 years) was small and not easily explained. It may be, in part, that subjects being younger at the initial visit had more time had more time during the follow-up period to develop nodules, but the Cox analysis takes this into account. Since there was no difference in the mean ages at radiation treatment, there would be a small difference in the calendar years in which the treatments were administered. As these treatments were administered from about 1940 to the early 1960s, it is possible that changes in instrumentation, methods of immobilization and other factors may have changed over time affecting the reported doses (Schneider et al. 1993). Anti-TPO antibodies (known as anti-microsomal antibodies in 1974) were not measured as thyroid nodules and thyroid cancer were the two endpoints of the study. Anti-Tg levels were measured as these antibodies were known to interfere with the thyroglobulin measurements (Schneider \& Pervos 1978).

Strengths of our study include the large number of radiation-exposed subjects and the long duration of follow-up, documented ages of radiation exposure and thyroid-specific doses, available medical histories including thyroid hormone use, and the surgical pathology reports of the benign and malignant nodules. Conversely, reliance on a first-generation assay for the assessment of the TSH and Tg levels, missing confounders (such as smoking), variation in follow-up by personal physicians and the changes in the thyroid imaging methodology over time are limitations of our study. Longitudinal TSH and Tg measurements were not part of the study and usually not obtained by the subject's physicians. However, these would be unlikely to introduce bias in the between-group comparisons of the factors analyzed here.
The results of this study suggest that elevated $\mathrm{Tg}$ levels provide an early indication of an increased risk of developing thyroid nodules in individuals exposed to childhood radiation and should encourage an increased and prolonged surveillance. However, Tg levels alone do not help differentiate between benign and malignant nodules. Further, our study indicates that baseline TSH levels are not associated with the risk of developing thyroid nodules and cancer in radiation-exposed subjects.

In summary, the clinical conclusions that could be drawn from our results include the following: (1) In distinction to other studies showing the risk that a thyroid nodule is malignant rises as the TSH increases, this is not the case for nodules following radiation exposure. (2) When subjects are first seen years after radiation exposure, it is uncertain how extensive their clinical evaluation should be and if ultrasonography is warranted. The higher the measured thyroglobulin, the higher the likelihood that a nodule is present, thus supporting thyroid imaging with ultrasound. (3) While a higher thyroglobulin is statistically associated with an increased chance that a nodule will be found during follow-up, the relationship is not sufficiently strong to independently recommend ultrasonography.

\section{Declaration of interest}

The authors declare that there is no conflict of interest that could be perceived as prejudicing the impartiality of the research reported.

\section{Funding}

This research did not receive any specific grant from any funding agency in the public, commercial or not-for-profit sector.

\section{References}

Abend M, Pfeiffer RM, Ruf C, Hatch M, Bogdanova TI, Tronko MD, Hartmann J, Meineke V, Mabuchi K \& Brenner AV 2013 Iodine-131 dose-dependent gene expression: alterations in both normal and tumour thyroid tissues of post-chernobyl thyroid cancers. British Journal of Cancer 109 2286-2294. (https://doi.org/10.1038/ bjc.2013.574)

Boelaert K, Horacek J, Holder RL, Watkinson JC, Sheppard MC \& Franklyn JA 2006 Serum thyrotropin concentration as a novel predictor of malignancy in thyroid nodules investigated by fineneedle aspiration. Journal of Clinical Endocrinology and Metabolism 91 4295-4301. (https://doi.org/10.1210/jc.2006-0527)

Cahoon EK, Rozhko A, Hatch M, Polyanskaya O, Ostroumova E, Tang M, Nadirov E, Yauseyenka V, Savasteeva I, McConnell RJ, et al. 2013 Factors associated with serum thyroglobulin levels in a population living in Belarus. Clinical Endocrinology 79 120-127. (https://doi.org/10.1111/cen.12107)

Carayon P, Thomas-Morvan C, Castanas E \& Tubiana M 1980 Human thyroid cancer: membrane thyrotropin binding and adenylate 
cyclase activity. Journal of Clinical Endocrinology and Metabolism $\mathbf{5 1}$ 915-920. (https://doi.org/10.1210/jcem-51-4-915)

Castro MR, Espiritu RP, Bahn RS, Henry MR, Gharib H, Caraballo PJ \& Morris JC 2011 Predictors of malignancy in patients with cytologically suspicious thyroid nodules. Thyroid 21 1191-1198. (https://doi.org/10.1089/thy.2011.0146)

Derwahl M, Broecker M \& Kraiem Z 1999 Clinical review 101: thyrotropin may not be the dominant growth factor in benign and malignant thyroid tumors. Journal of Clinical Endocrinology and Metabolism 84 829-834.

Favus MJ, Schneider AB, Stachura ME, Arnold JE, Ryo UY, Pinsky SM, Colman M, Arnold MJ \& Frohman LA 1976 Thyroid cancer occurring as a late consequence of head-and-neck irradiation. Evaluation of 1056 patients. New England Journal of Medicine 294 1019-1025. (https://doi.org/10.1056/NEJM197605062941901)

Frohman LA, Baron MA \& Schneider AB 1982 Plasma immunoreactive TSH: spurious elevation due to antibodies to bovine TSH which cross-react with human TSH. Metabolism: Clinical and Experimental 31 834-840. (https://doi.org/10.1016/0026-0495(82)90083-X)

Gudmundsson J, Sulem P, Gudbjartsson DF, Jonasson JG, Sigurdsson A, Bergthorsson JT, He H, Blondal T, Geller F, Jakobsdottir M, et al. 2009 Common variants on 9q22.33 and 14q13.3 predispose to thyroid cancer in European populations. Nature Genetics 41 460-464. (https://doi.org/10.1038/ng.339)

Gudmundsson J, Sulem P, Gudbjartsson DF, Jonasson JG, Masson G, He H, Jonasdottir A, Sigurdsson A, Stacey SN, Johannsdottir H, et al. 2012 Discovery of common variants associated with low TSH levels and thyroid cancer risk. Nature Genetics 44 319-322. (https://doi. org/10.1038/ng.1046)

Haymart MR, Repplinger DJ, Leverson GE, Elson DF, Sippel RS, Jaume JC \& Chen H 2008 Higher serum thyroid stimulating hormone level in thyroid nodule patients is associated with greater risks of differentiated thyroid cancer and advanced tumor stage. Journal of Clinical Endocrinology and Metabolism 93 809-814. (https://doi. org/10.1210/jc.2007-2215)

Huang H, Rusiecki J, Zhao N, Chen Y, Ma S, Yu H, Ward MH, Udelsman R \& Zhang Y 2017 Thyroid-stimulating hormone, thyroid hormones, and risk of papillary thyroid cancer: a nested case-control study. Cancer Epidemiology, Biomarkers and Prevention 26 1209-1218.

Ichikawa Y, Saito E, Abe Y, Homma M \& Muraki T 1976 Presence of TSH receptor in thyroid neoplasms. Journal of Clinical Endocrinology and Metabolism 42 395-398. (https://doi.org/10.1210/jcem-42-2-395)

Kim KW, Park YJ, Kim EH, Park SY, Park do J, Ahn SH, Park do J, Jang HC \& Cho BY 2011 Elevated risk of papillary thyroid cancer in Korean patients with Hashimoto's thyroiditis. Head and Neck $\mathbf{3 3}$ 691-695.

Kitahara CM 2017 New evidence on the association between prediagnostic thyroid-stimulating hormone levels and thyroid cancer risk. Cancer Epidemiology, Biomarkers and Prevention 8 1163-1164. (https://doi.org/10.1158/1055-9965.EPI-17-0329)

Kitahara CM \& Sosa JA 2016 The changing incidence of thyroid cancer. Nature Reviews Endocrinology 12 646-653. (https://doi.org/10.1038/ nrendo.2016.110)

Lando A, Holm K, Nysom K, Krogh Rasmussen A, Hoier Madsen M, Feldt-Rasmussen U \& Muller J 2003 Serum thyroglobulin as a marker of thyroid neoplasms after childhood cancer. Acta Paediatrica 92 1284-1290. (https://doi.org/10.1111/j.1651-2227.2003.tb00498.x)

NCRP 2009 Ionizing Radiation Exposure of the Population of the United States. NCRP Report No. 160. Bethesda, MD, USA: National Council on Radiation Protection and Measurements.

Peters KO, Tronko M, Hatch M, Oliynyk V, Terekhova G, Pfeiffer RM, Shpak VM, McConnell RJ, Drozdovitch V, et al. 2017 Factors associated with serum thyroglobulin in a Ukrainian cohort exposed to iodine-131 from the accident at the Chernobyl Nuclear Plant. Environmental Research 156 801-809. (https://doi.org/10.1016/j. envres.2017.04.014)
Pujol P, Daures JP, Nsakala N, Baldet L, Bringer J \& Jaffiol C 1996 Degree of thyrotropin suppression as a prognostic determinant in differentiated thyroid cancer. Journal of Clinical Endocrinology and Metabolism 81 4318-4323. (https://doi.org/10.1210/ jcem.81.12.8954034)

Rinaldi S, Plummer M, Biessy C, Tsilidis KK, Ostergaard JN, Overvad K, Tjonneland A, Halkjaer J, Boutron-Ruault MC, Clavel-Chapelon F, et al. 2014 Thyroid-stimulating hormone, thyroglobulin, and thyroid hormones and risk of differentiated thyroid carcinoma: the EPIC study. Journal of the National Cancer Institute 106 dju097. (https://doi. org/10.1093/jnci/dju097)

Ron E, Lubin JH, Shore RE, Mabuchi K, Modan B, Pottern LM, Schneider AB, Tucker MA \& Boice JD Jr 1995 Thyroid cancer after exposure to external radiation: a pooled analysis of seven studies. Radiation Research 141 259-277. (https://doi.org/10.2307/3579003)

Satta MA, De Rosa G, Testa A, Maussier ML, Valenza V, Rabitti C, Saletnich I, D'Ugo D \& Picciocchi A 1993 Thyroid cancer in suppressed contralateral lobe of patients with hot thyroid nodule. European Journal of Cancer 29A 1190-1192. (https://doi.org/10.1016/ S0959-8049(05)80313-2)

Schneider AB, Favus MJ, Stachura ME, Arnold JE, Ryo UY, Pinsky S, Colman M, Arnold MJ \& Frohman LA 1977 Plasma thyroglobulin in detecting thyroid carcinoma after childhood head and neck irradiation. Annals of Internal Medicine 86 29-34. (https://doi. org/10.7326/0003-4819-86-1-29)

Schneider AB \& Pervos R 1978 Radioimmunoassay of human thyroglobulin: effect of antithyroglobulin autoantibodies. Journal of Clinical Endocrinology and Metabolism 47 126-137. (https://doi. org/10.1210/jcem-47-1-126)

Schneider AB, Shore-Freedman E, Ryo UY, Bekerman C \& Pinsky SM 1985 Prospective serum thyroglobulin measurements in assessing the risk of developing thyroid nodules in patients exposed to childhood neck irradiation. Journal of Clinical Endocrinology and Metabolism $\mathbf{6 1}$ 547-550. (https://doi.org/10.1210/jcem-61-3-547)

Schneider AB, Ron E, Lubin J, Stovall M \& Gierlowski TC 1993 Doseresponse relationships for radiation-induced thyroid cancer and thyroid nodules: evidence for the prolonged effects of radiation on the thyroid. Journal of Clinical Endocrinology and Metabolism $\mathbf{7 7}$ 362-369. (https://doi.org/10.1210/jcem.77.2.8345040)

Schneider AB, Bekerman C, Leland J, Rosengarten J, Hyun H, Collins B, Shore-Freedman E \& Gierlowski TC 1997 Thyroid nodules in the follow-up of irradiated individuals: comparison of thyroid ultrasound with scanning and palpation. Journal of Clinical Endocrinology and Metabolism 82 4020-4027. (https://doi. org/10.1210/jcem.82.12.4428)

Sinnott B, Ron E \& Schneider AB 2010 Exposing the thyroid to radiation: a review of its current extent, risks, and implications. Endocrine Reviews 31 756-773. (https://doi.org/10.1210/er.2010-0003)

Suzuki S, Nakamura I, Suzuki S, Ohkouchi C, Mizunuma H, Midorikawa S, Fukushima T, Ito Y, Shimura H, Ohira T, et al. $2016 a$ Inappropriate suppression of thyrotropin concentrations in young patients with thyroid nodules including thyroid cancer: the Fukushima Health Management Survey. Thyroid 26 717-725. (https://doi.org/10.1089/thy.2015.0499)

Suzuki S, Suzuki S, Fukushima T, Midorikawa S, Shimura H, Matsuzuka T, Ishikawa T, Takahashi H, Ohtsuru A, Sakai A, Hosoya M, et al. $2016 b$ Comprehensive survey results of childhood thyroid ultrasound examinations in Fukushima in the first four years after the Fukushima Daiichi nuclear power plant accident. Thyroid 26 843-851. (https://doi.org/10.1089/thy.2015.0564)

Takahashi M, Saenko VA, Rogounovitch TI, Kawaguchi T, Drozd VM, Takigawa-Imamura H, Akulevich NM, Ratanajaraya C, Mitsutake N, Takamura N, et al. 2010 The FOXE1 locus is a major genetic determinant for radiation-related thyroid carcinoma in Chernobyl. Human Molecular Genetics 19 2516-2523. (https://doi.org/10.1093/ $\mathrm{hmg} / \mathrm{ddq} 123)$ 
Thoresen SO, Myking O, Glattre E, Rootwelt K, Andersen A \& Foss OP 1988 Serum thyroglobulin as a preclinical tumour marker in subgroups of thyroid cancer. British Journal of Cancer 57 105-108. (https://doi.org/10.1038/bjc.1988.19)

Van Herle AJ, Uller RP, Matthews NI \& Brown J 1973 Radioimmunoassay for measurement of thyroglobulin in human serum. Journal of Clinical Investigation 52 1320-1327. (https://doi.org/10.1172/ JCI107303)

Veiga LH, Holmberg E, Anderson H, Pottern L, Sadetzki S, Adams MJ, Sakata R, Schneider AB, Inskip P, Bhatti P, et al. 2016 Thyroid cancer after childhood exposure to external radiation: an updated pooled analysis of 12 studies. Radiation Research 185 473-484. (https://doi. org/10.1667/RR14213.1)
Wheatley S, Sovacool B \& Sornette D 2017 Of disasters and dragon kings: a statistical analysis of nuclear power incidents and accidents. Risk Analysis 37 99-115. (https://doi.org/10.1111/risa.12587)

Williams TC, Kelijman M, Crelin WC, Downs TR \& Frohman LA 1988 Differential effects of somatostatin (SRIH) and a SRIH analog, SMS 201-995, on the secretion of growth hormone and thyroidstimulating hormone in man. Journal of Clinical Endocrinology and Metabolism 66 39-45. (https://doi.org/10.1210/jcem-66-1-39)

Witczak J, Taylor P, Chai J, Amphlett B, Soukias JM, Das G, Tennant BP, Geen J \& Okosieme OE 2016 Predicting malignancy in thyroid nodules: feasibility of a predictive model integrating clinical, biochemical, and ultrasound characteristics. Thyroid Research 94. (https://doi.org/10.1186/s13044-016-0033-y)

Received in final form 15 January 2018

Accepted 14 February 2018

Accepted Preprint published online 14 February 2018
(C) 2018 Society for Endocrinology Published by Bioscientifica Ltd. Printed in Great Britain 